ARTICLE

\title{
Becoming Partners: Faculty Come to Appreciate Undergraduates as Teaching Partners in a Service-Learning Teaching Assistant Program
}

\author{
* Gail S. Begley ${ }^{a}$, Rebecca E. Berkey ${ }^{b}$, Lisa M. Roe ${ }^{b}$, and Hilary E. Y. Schuldt ${ }^{c}$ \\ a Department of Biology, Northeastern University, Boston, Massachusetts, USA \\ ${ }^{b}$ Center of Community Service, Northeastern University, Boston, Massachusetts, USA \\ ${ }^{\circ}$ Center for Advancing Teaching and Learning Through Research, Northeastern University, \\ Boston, Massachusetts, USA
}

Contact: g.begley@northeastern.edu

\section{ABSTRACT}

This study examined the relationships between faculty and their teaching assistants in an undergraduate teaching assistant program developed at Northeastern University in the US to ease the challenges faculty faced in incorporating Service-Learning into their teaching. Feedback from faculty suggested that the undergraduates trained to assist them with purely logistical tasks were becoming partners in teaching. To explore the relationship between faculty and their teaching assistants and better understand how the faculty may have come to view the teaching assistants as partners, we conducted indepth interviews with faculty across a range of academic disciplines and experience levels who had worked with one or more undergraduate teaching assistants. The data revealed that while the faculty participants did appreciate receiving logistical assistance with Service-Learning, they also benefited from partnering with students as colleagues who supported their teaching more broadly. We also found that faculty viewed the partnership in different ways depending on their level of experience with ServiceLearning pedagogy.

\section{KEYWORDS}

partnership development, undergraduate teaching assistants, service-learning, students as co-teachers, students as colleagues

\section{INTRODUCTION}

The purpose of this study was to explore the impact of working with specially trained undergraduate teaching assistants (TAs) on faculty using Service-Learning (S-L). Service- 
Learning is a type of experiential learning in which students engage with community-based organizations and integrate the learning that occurs in the community and the classroom in order to meet both community-identified goals and course learning objectives. The decision to support S-L faculty with teaching assistants reflects specific input from faculty on the barriers and challenges that they perceived in teaching S-L courses, in which additional work is required to establish relationships with community organizations, place students as volunteers with those organizations, and oversee the community service that the students do. Employment of an undergraduate teaching assistant trained to help with these logistical challenges was viewed as a practical means of supporting faculty in implementing $\mathrm{S}-\mathrm{L}$.

However, while responses from several years of end-of-semester S-L faculty evaluations indicated that the goal of providing logistical support to faculty through TAs was largely being achieved, comments from faculty further suggested that they were developing rich relationships with their TAs. These comments hinted at a hidden benefit to faculty who might view the TA more as a partner consistent with the growing movement and literature within higher education on the value of Students as Partners (SaP) initiatives (reviewed by MercerMapstone et al., 2017). Low response rates and length limitations to faculty comments did not allow us to clearly identify or deeply understand this phenomenon. We thus pursued the following research question: How does working with an undergraduate Service-Learning

\section{Teaching Assistant impact faculty?}

We used in-depth, semi-structured interviews to explore how S-L faculty from a variety of disciplines experienced working with TAs, allowing us to determine if the working relationship was a supervisory and logistical one, as originally intended, or a teaching partnership, as preliminary evidence suggested. Our analysis revealed the development of what the faculty members viewed as collegial relationships that enhanced their teaching and learning and supported faculty innovation in ways that were not originally envisioned. The nature of these partnerships evolved in different ways depending, at least in part, on the level of experience that faculty had with S-L pedagogy. Thus, faculty who had entered into a transactional relationship with a student found that relationship morphing into a more egalitarian partnership.

Importantly, our study focuses exclusively on faculty perceptions of their relationships with undergraduate teaching assistants. In their recent systematic review of the Students as Partners literature, Mercer-Mapstone et al. (2017) noted that the preponderance of articles reported outcomes for students, rather than staff: "This student-centric reporting of partnership may potentially reflect that SaP can be seen as a strategy to enhance the student experience, thereby prioritizing the student response. This does, however, potentially communicate a deficit mindset derived from a history of student engagement rhetoric, which implies that engagement, and by extension partnership, is something 'done to' rather than 'done with' students" (Matthews, 2016). Interrogating faculty perceptions of how they work with undergraduate teaching assistants, how they value these interactions, and how their relationships develop can begin to address this gap in the literature. 


\section{SERVICE-LEARNING PROGRAM STRUCTURE}

Twelve years ago, as the Service-Learning Program at Northeastern University was institutionalized and growing, faculty identified logistical concerns as the biggest barrier to adopting this pedagogical approach, not unlike the barriers identified in incorporating other high-impact practices (Bass, 2012; Kuh, Donnell, \& Schneider, 2017). Acting on this feedback, the Service-Learning Teaching Assistant (S-LTA) Program was established to assist faculty with two main responsibilities: placing students in service or project roles and managing community partnerships. Since that time, the Service-Learning Program within the Center of Community Service has recruited, trained, and mentored students (predominantly undergraduates) to serve as teaching assistants for S-L courses.

Any faculty member teaching a course with an S-L component is offered the support of an S-LTA who is hired, trained, compensated, and supported by the Service-Learning Program. While most faculty choose to participate in to working with an S-LTA, several choose not to each semester for various reasons. Faculty members who opt in have several options for hiring a TA: recruit a former student of their own, identify qualities or characteristics they are seeking in an S-LTA who will be recruited by program staff, or allow program staff to assign an S-LTA based on availability.

\section{S-L teaching assistant recruitment, compensation, training, and responsibilities}

Each semester, approximately 40-45 students serve as S-LTAs with the program. Students are recruited from across the student body, though most apply to the program because they enjoyed their own service-learning course, were recruited directly by their faculty member to work alongside them, or are highly engaged in service and leadership through other avenues. Most S-LTAs support a single course and therefore an individual faculty member, cohort of students, and associated community partnerships.

S-LTAs are offered a variety of compensation options to choose from, including a $\$ 1,000$ stipend, work-study (if they are eligible), unpaid directed or independent study (which must be for academic credit and arranged through an academic department), an unpaid internship or practicum (which must be for academic credit), or volunteering (typically chosen by students who are required to complete service as part of a scholarship requirement). Approximately 75$85 \%$ of candidates choose the stipend, which is funded directly by the Service-Learning Program, though two academic departments fund their own S-LTAs.

S-LTAs complete a full training that includes topics such as foundations of servicelearning, asset-based community development, responsibilities and expectations of their role, introducing service-learning to students, and professionalism and communication. They then meet weekly throughout the semester as described below, and continue to train on topics relevant to their role as a S-LTA or their development as a student leader.

Because the goals and partnerships of each service-learning course are unique, the way faculty members work with their S-LTAs varies. S-LTAs are expected to attend nearly every class session, though their other responsibilities can include introducing service-learning to students during the first week of class, facilitating reflection discussions and activities in class, codesigning reflection prompts, managing communication between community partners and students, and providing logistical support for partnerships such as assigning students to 
community partners and arranging orientation dates. Faculty members are not required to complete any training to work with an S-LTA, but rather are provided resources such as the program's learning outcomes and S-LTA responsibilities and expectations.

\section{Establishing community partnerships for S-L courses}

In addition to supporting faculty by providing, training, and supporting S-LTAs, the Service-Learning Program has a central, formal structure for community partnership setup. The Service-Learning Program matches community partners with faculty members and courses that are likely able to meet community-identified goals, provides space for partners and faculty members to connect through a Partnership Orientation at the beginning of the semester, and facilitates multiple check-ins and an evaluation process.

Each semester, S-L Program staff circulate a Request for Partnerships application to community partners that they use to make preliminary recommendations to faculty about potential partnerships that will fit both course learning objectives and community goals. After faculty select or confirm the partnerships, they work out additional details with the community partners.

A critical part of the S-LTA's role is to serve as a point person for the community partnership and assign students from the class to community partner organizations for their projects or service roles. The handoff from faculty oversight to S-LTA oversight of course partnerships usually happens as the semester begins, once the S-LTA is trained. At that point, the S-LTA coordinates the partnerships and monitors them throughout the semester to address any issues that come up and ensure their success.

\section{Program size and scaling}

When the S-LTA Program began, there were fewer than $20 \mathrm{~S}-\mathrm{L}$ course sections each year. The Service-Learning Program now supports approximately $120 \mathrm{~S}-\mathrm{L}$ course sections each year, which means many facets of the program have evolved and scaled over the last decade. The S-LTA Program was scalable over time due to our peer leadership model, in which small cohorts of TAs are led by Service-Learning Team Managers, who are senior S-LTAs. Team Managers help guide S-LTAs through real-time challenges and celebrate in their successes as they build community among their peers. Team Managers also coach the S-LTAs on integrating reflection into the curriculum, building professional relationships with community partners, evolving their role in the classroom, developing professional communication skills, and working with their faculty members.

\section{FACULTY DEVELOPMENT - BARRIERS TO TEACHING INNOVATION}

A variety of barriers to adopting pedagogical innovations such as service-learning have been identified in the literature, including the absence of clear communication of goals and alignment with faculty values and concerns (Koslowski, 2006), opportunities to gain expertise without an onerous time commitment (Baxley, Probst, Schell, Bogdewic, \& Cleghorn, 1999; Dotolo, 1999; Koslowski, 2006), institutional commitment to innovation (Young, Shinnar, Ackerman, Carruthers, \& Young, 2007), and incentives for participation (Lazerson, Wagener, \& Shumanis, 2000). 
In the specific context of $S-L$ as a pedagogical innovation, the barriers related to time commitment are magnified, as faculty not only have an initial outlay of time to learn about a new pedagogy and to redesign their courses, but also need to commit extra time every time they teach the S-L course. Faculty must establish and maintain relationships with community partners, place students with community partners each time they teach the course, oversee student placements, integrate student service experiences into the classroom, and more. A survey of over 500 faculty at 43 institutions in Ohio assessed factors that motivated or deterred faculty from using S-L in their teaching (Abes, Jackson, \& Jones, 2002). Four concerns were identified as strong deterrents to faculty who had never used S-L before: logistical challenges associated with community partnership, lack of knowledge of S-L pedagogy, perceived irrelevance to courses taught, and lack of release time to develop an S-L course.

Bringle, Hatcher, and Games (1997) point out that "the task of persuading faculty to become engaged in developing and implementing a service-learning course is distinct from working with those faculty to further their development as instructors and professionals" ( $p$. 46). This was supported by Abes et al.'s study, in which time, logistics, funding, and faculty incentives were most often identified as possible deterrents to continued use of S-L. Understanding of S-L and relevance to their courses were not major impediments to continued use of S-L (Abes et al., 2002). This highlights the challenge that many faculty members face as they must decide whether to pursue meaningful ways to help students achieve learning outcomes, or focus on research, publications, and other time commitments as their performance, promotion, and/or tenure guidelines demand.

\section{UNDERGRADUATE TEACHING ASSISTANTS}

Owen's (2011) review of the literature on undergraduate teaching assistants (UTAs) noted that although the most obvious benefit for faculty in working with UTAs was help with course management, many other benefits accrued for faculty who were willing to view UTAs as collaborators. For example, Fingerson and Culley's (2001) interviews of 12 Sociology faculty explored whether UTAs can promote the goals of learner-centered pedagogy. Although some faculty focused on the importance of mentoring UTAs and exposing them to the profession, most focused on how they had gained a collaborator in their teaching, which led to both a less isolated teaching experience and a more learner-centered approach.

Related to these relationships between faculty and student teaching assistants are faculty-student partnerships, as defined by the growing Students as Partners movement and body of research within higher education (Cook-Sather, Bovill, \& Felten, 2014; Healey, Flint, \& Harrington, 2014; Mercer-Mapstone et al., 2017). Similar benefits for faculty have been found when partnering with undergraduates in roles that go beyond that of a traditional teaching assistant and in ways that uphold "a collaborative, reciprocal process through which all participants have the opportunity to contribute equally, although not necessarily in the same ways, to curricular or pedagogical conceptualization, decision-making, implementation, investigation, or analysis" (Cook-Sather et al., 2014, pp. 6-7). Healey et al. (2014) identify two broad ways that students engage with faculty in partnership: learning, teaching, and research; and enhancement of learning and teaching practice and policy. Our S-LTA program was created to engage students in the logistics of teaching and learning associated specifically with service- 
learning, but our interviews with faculty revealed that the relationship also developed in ways that enhanced practice and influenced faculty experience in the realm of S-L and beyond.

Cook-Sather and colleagues (2014) explored the benefits of collaboration with undergraduate students to improve teaching and learning in the context of a program that paired faculty with undergraduate student consultants who are not enrolled in the courses that the faculty are teaching. They identified three primary outcomes of these faculty-consultant interactions, writing that faculty "describe how, through working in partnership with students, they develop a greater awareness of their pedagogical goals, an enhanced ability to analyze those goals, and an increased capacity to name what they intend and how they strive to achieve it" (p. 117). In fact, these authors observed that the faculty and students involved in such partnerships often experience similar outcomes in the broad areas of engagement, metacognitive awareness, and enhanced classroom experiences.

At our institution, a structured S-LTA program was intended to promote the continued and expanded use of S-L pedagogies by providing faculty with logistical support, as time commitment and practical challenges have been identified as a deterrent to both initial and continued use of service-learning. Critical components of this program were designed specifically to address the concerns raised in earlier studies regarding recruitment, training, and management of teaching assistants (Eby \& Gilbert, 2000; Owen, 2011). Notably, the student consultants described by Cook-Sather and colleagues (Cook-Sather et al., 2014; Cook-Sather \& Motz-Storey, 2016) prepare for their responsibilities by participating in an initial orientation and subsequent weekly meetings with the program director and other student consultants, a structure similar to that used to prepare and provide ongoing support for our S-LTAs as well. On the other hand, the role of the TA was never envisioned as that of a partner in co-creation of teaching and learning as described by Bovill, Cook-Sather, and Felten (2011), but preliminary data suggested that such partnerships might develop organically.

\section{METHODS}

Our study was driven by the research question: How does working with an undergraduate Service-Learning Teaching Assistant impact faculty? This question arose from formal and informal feedback from S-L faculty that suggested that at least some faculty were developing rich partnerships with their S-LTAs and that the resultant benefits extended beyond easing the burden of managing community placements. Coupled with our own classroom observations and informal discussion with other faculty, our program evaluation data (results of end-of-semester surveys provided to all faculty teaching S-L courses) helped to initiate further research on this topic and informed our interview protocol.

We designed a qualitative, phenomenological interview-based study in order to explore the lived experiences of our S-L faculty members - and their constructed understanding of these experiences - in relation to their S-LTAs. Data were gathered through approximately 45minute, semi-structured interviews designed to explore more deeply how faculty viewed the impacts of working with an undergraduate TA on their teaching. We also delved further into the nature and development of the faculty member's relationship with the S-LTA. Interviews were conducted by two of the four researchers (a faculty member who teaches an S-L course and an educational developer with the Teaching and Learning Center). In order to limit socially 
desirable responses, the two researchers who are S-LTA Program administrators did not conduct interviews.

After obtaining Institutional Review Board approval and the written consent of all participants, we conducted and recorded interviews. An outside transcriber transcribed these recordings, which we then analyzed using the Dedoose software package. In reading through the transcripts, we first developed units of general meaning and then generated patterns and relationships of meaning (Creswell, 2003; Moustakas, 1994) through which we defined themes for our coding process. We refined and calibrated our codebook via an iterative process in which multiple researchers read and coded transcripts three times to ensure inter-coder agreement and reliability (Creswell, 2003).

\section{Participants}

We recruited faculty who had previously worked directly with one or more S-LTAs in teaching a course or courses at Northeastern University for this study. We interviewed 18 faculty members from six different colleges within the university (see Table 1; we have not included participant gender and college in order to minimize risk of subject identification).

Table 1: Faculty participant descriptors

\begin{tabular}{|l|l|l|}
\hline $\begin{array}{l}\text { Participant } \\
\text { Number }\end{array}$ & Length of Time with Program & \\
\hline 1 & Experienced & Broad Disciplinary Areas \\
\hline 2 & Experienced & Social Sciences/Humanities \\
\hline 3 & New & Social Sciences/Humanities \\
\hline 4 & Experienced & STEM \\
\hline 5 & Experienced & Social Sciences/Humanities \\
\hline 6 & Experienced & Social Sciences/Humanities \\
\hline 7 & New & Social Sciences/Humanities \\
\hline 8 & Experienced & Social Sciences/Humanities \\
\hline 9 & New & Social Sciences/Humanities \\
\hline 10 & New & STEM \\
\hline 11 & Experienced & Social Sciences/Humanities \\
\hline 12 & New & STEM \\
\hline 13 & New & STEM \\
\hline 14 & New & STEM \\
\hline 15 & New & Social Sciences/Humanities \\
\hline 16 & New & Social Sciences/Humanities \\
\hline 17 & Experienced & Social Sciences/Humanities \\
\hline 18 & New & Social Sciences/Humanities \\
\hline
\end{tabular}

${ }^{1} \mathrm{New}$ is defined as 1-3 semesters teaching with S-L and experienced as 4+ semesters.

${ }^{2}$ To protect the identity of participants we categorized disciplinary areas broadly here.

Six of the 18 participants were male; 12 were female. Participants' academic disciplines included a variety of fields across the social sciences, humanities, health sciences, natural 
sciences, mathematics, and engineering. Eight faculty members were new to $S$-L, meaning that they had one to three semesters experience teaching with $S-L$ at the time of the interview, whereas ten faculty members had four or more semesters of experience. Additionally, 11 faculty members had self-selected to teach their S-L courses, whereas seven were required to use S-L based on the course they were assigned to teach by their department or college. Lastly, faculty members had been paired with their S-LTA through the variety of means previously described.

\section{FINDINGS}

The two themes that most often emerged from the interview data were relationshipbuilding and course structure. In exploring these themes and the subthemes within them, we examined both the emphasis that faculty gave to themes (code frequency) and the percentage of participants who mentioned a particular theme (code presence or absence). This analysis allowed us to better understand the experience of individual faculty and to determine whether particular themes were universal across all faculty interviewed or were spoken about repeatedly by only some faculty.

\section{Theme 1: Relationship-building}

Several benefits of the S-LTA/faculty relationship emerged as important to faculty when thinking about the S-LTA Program (see Table 2). Nearly three-quarters of the relationship theme comments focused on the faculty-TA connection itself. While on the one hand, this is not surprising when inquiring about the experience of working with a TA, the responses often dealt with the nature of the personal relationship, rather than simply transactional supervisorassistant interactions.

Table 2: Types of relationships discussed in faculty interviews

\begin{tabular}{|l|l|}
\hline Relationship & Frequency $^{1}$ \\
\hline Faculty-S-LTA & $74 \%$ \\
\hline S-LTA-Students & $14 \%$ \\
\hline S-LTA-Community Partner & $10 \%$ \\
\hline Faculty-Students & $2 \%$ \\
\hline Faculty-Community Partner & $<1 \%$ \\
\hline
\end{tabular}

${ }^{1}$ Percent of total codes assigned to relationship development ( $N=513$ ) across all interviews.

Although the frequency data in Table 2 show that nearly three-quarters of the total comments made about how relationships developed were focused on the faculty-S-LTA partnership, presence/absence analysis (see Figure 1) indicates that development of relationships between the TA and the faculty member, between the TA and the students, and between the TA and the community partners were mentioned at least once during the interview by more than $80 \%$ of the individual participants. So although faculty spoke more frequently about their own partnership with the TA, most faculty also chose to describe the relationships that TAs were establishing with others. Nearly two-thirds of the faculty highlighted ways that interacting with an S-LTA impacted the development of their own relationships with students. In contrast, only $20 \%$ of participants mentioned ways in which their 
relationships with community partners evolved, which may reflect the extent to which TAs acted as community partner liaisons for faculty.

Figure 1: Presence of relationship development theme in individual interviews ( $N=18$ interviews)

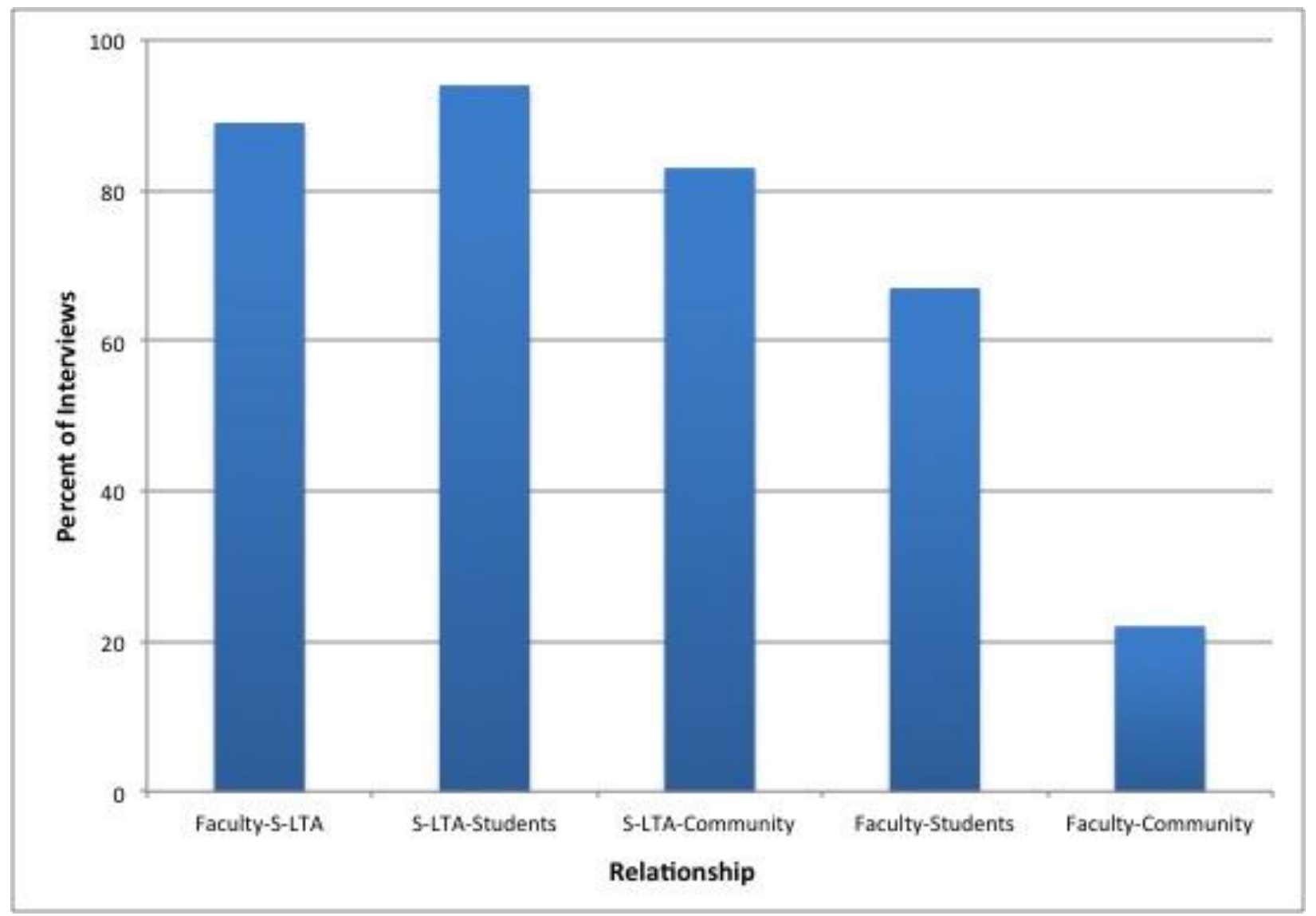

The nature of the faculty-S-LTA relationship

Notably, our analysis of the faculty-S-LTA relationship theme revealed a preponderance of comments describing the collegial nature of the relationship. Despite the fact that the TAs were undergraduates, many faculty came to view them as co-teachers or colleagues who helped improve the course and provide essential feedback (see Table 3). In looking at the frequency of secondary code usage within the faculty-S-LTA relationship theme, $75 \%$ of the time faculty used the language of a collegial relationship and only $13 \%$ of the time spoke in terms of a supervisory relationship. 
Table 3: Subthemes of faculty-S-LTA relationships

\begin{tabular}{|l|l|}
\hline Nature of Relationship & Frequency $^{1}$ \\
\hline Co-teachers or Colleagues & $75 \%$ \\
\hline Supervisory & $13 \%$ \\
\hline Foundation for Future Collaboration & $5 \%$ \\
\hline
\end{tabular}

${ }^{1}$ Percent of total codes assigned to Faculty-S-LTA relationships $(\mathrm{N}=380)$ across all interviews

\section{Teaching assistant as colleague}

Analysis of the presence or absence of subthemes in individual faculty interviews revealed one relationship code that was found in every interview: benefits that faculty felt that they had gained from interacting with the TA as a colleague or co-teacher. In this subtheme, faculty sometimes described collegial interactions with their TAs specific to the context of teaching with service-learning, for example:

So [the TA] was very much involved in the process of what the class would look like and in developing the relationship with our service-learning partner (Participant 1).

I've never had a TA of any kind before. So just to have: $A$, just to have a TA; but $B$, to have a TA who's focused on service-learning. You know, that was just a really beautiful combination and a gift really (Participant 7).

When I originally was designing the course I was at a very different level. And I kept adjusting what I was doing with the course. And I didn't really have a good idea of what the heck service-learning was and the interactions of everything. So [the TA] supplied me with some rubrics. And I talked to her about that sort of thing (Participant 12).

On the other hand, many comments centered on collaborating with the TA in teaching the course more broadly, for example:

I feel that [the TA] part has been incredibly informative and instructive. It's another set of eyes in the classroom. It's a student perspective on what's happening in the classroom. It's an essential conduit for feedback especially if they have content expertise. . . So affirmation, friendship, and again, the sense of community that we're, we're doing good work together and we're gonna continue to do this good work together (Participant 1).

[The TA asks:] "Why did you do it that way?" And that forces me to have to share my thinking. . . I love collaborating. And I love thinking out loud and bouncing back and forth. My ideas get richer. My creativity gets heard (Participant 5).

And so we've done more of the planning together. We've had a couple of meetings where we planned the classes and [the TA] talks about, "You know, these are some 
activities that we can bring or I would love to look for something for this particular theme" (Participant 14).

There were at least two or three times during the semester where I felt like the TAs the culture of our dynamics - were not so hierarchical that they didn't feel like they could call me out, which I really was proud of. And there was at least two or three times in the semester where somebody gave me like advice that was really directional. It really changed my thinking. At least, at least it might have been a very small thing. But it actually felt like I was learning. I learned something about how to approach [my teaching] (Participant 18).

\section{Theme 2: Service-learning course structure}

Not surprisingly, the second primary theme that we observed was the value placed on the TA's practical contributions in terms of supporting the Service-Learning course structure, i.e., providing logistical support to the faculty member to make S-L easier to implement. Some faculty involved their TA in developing a new course, creating or co-creating an additional pedagogical innovation, or modifying some aspect of the course. However, most of the comments within this theme were focused on implementation of the S-L component of the class, for example, placing students in their service roles with community partners, facilitating reflection activities, and providing feedback to students regarding their service. In fact, implementation was the only secondary code other than the benefit of TA as colleague/coteacher that was found at least once in every faculty interview. Because the S-LTA Program was designed with the intent of providing instructors with logistical assistance in order to make it easier for faculty to adopt and maintain S-L as part of their pedagogy, this result indicates that the program was functioning as intended and that faculty found the support beneficial, for example:

I like working with the TA because of logistics. Because it's a lot of coordinating. I have all these big plans about these relationships with the partner organizations that I just couldn't do, because of time. So anyway, the logistics of having a TA, was really helpful (Participant 14).

For some faculty, logistical support was the primary benefit of having an S-LTA, for example:

If I had voice in requesting [the TA], I would prefer to have someone who was very organized and logistically inclined over somebody who was like maybe really passionate, but not as together on the logistical element (Participant 18).

In contrast, some faculty felt that knowledge of the discipline, and not just of S-L practice, was essential. One faculty member explained why s/he doesn't think that partnering with an S-LTA focused on logistics was as beneficial as selecting a former student who was both trained by the S-LTA program and familiar with the course: 
I hope after this next spring semester that I'm in a stretch where I'm not having to use a service-learning TA that isn't a former student of mine. Because while they take care of the logistical aspects of service-learning, I feel like the learning experience for the students is quite honestly compromised. Because it, it feels much more like an add-on. Because their role is an add-on. They haven't taken the course. They don't understand the content. In many cases, they don't understand me (Participant 4).

Regardless of whether or not they emphasized logistics over other TA contributions, most faculty were not sure they would continue using S-L in their courses without this resource, consistent with the earlier feedback from service-learning faculty through program evaluations and informal conversations that informed our research question. Here is how one faculty member explains that choice in terms of balancing overall workload:

So I would be in charge of all the logistics. I think that would be the biggest barrier to moving forward without a TA. If I was just teaching a regular course load and wasn't doing anything else, wasn't engaged in research, then that burden, I think, would probably be manageable. But the way that my teaching and my research load has been lately, I'm feeling like I don't have the capacity to engage in the logistics of the coordination process. I feel like that's such a huge benefit that is off my shoulders that if it were on my shoulders, that would be a challenge (Participant 2).

\section{Impact of faculty experience on the development of a partnership with the TA}

We also analyzed associations between participant demographics and code usage. The participant descriptors included disciplinary area, whether the faculty member chose to incorporate $S-L$ or was assigned to an S-L course, how involved the faculty member was in selecting the TA, and how long the faculty member had been teaching $S-L$ courses. Only the last descriptor-length of experience with $S$-L pedagogy-produced a unique pattern of subthemes (Figure 2). Newer S-L faculty, defined as having fewer than four semesters of S-L teaching experience, were more likely to talk about implementation - the logistics of using S-L in the course-and the challenges of navigating a collegial relationship with an undergraduate TA. More experienced S-L faculty focused less on the logistics overall and when discussing the TA as a colleague or co-teacher, these faculty emphasized the benefits and de-emphasized challenges relative to their less experienced colleagues. Experienced S-L faculty also spoke more about feelings of pride in what their TAs accomplished. The latter observation may simply reflect the fact that faculty with a longer history with the TA program had more opportunities to see the longitudinal development of TAs as they maintained these relationships over time. 
Figure 2: Frequencies of $\operatorname{codes}^{1}$ that differentiate faculty by extent of $S$-L teaching experience

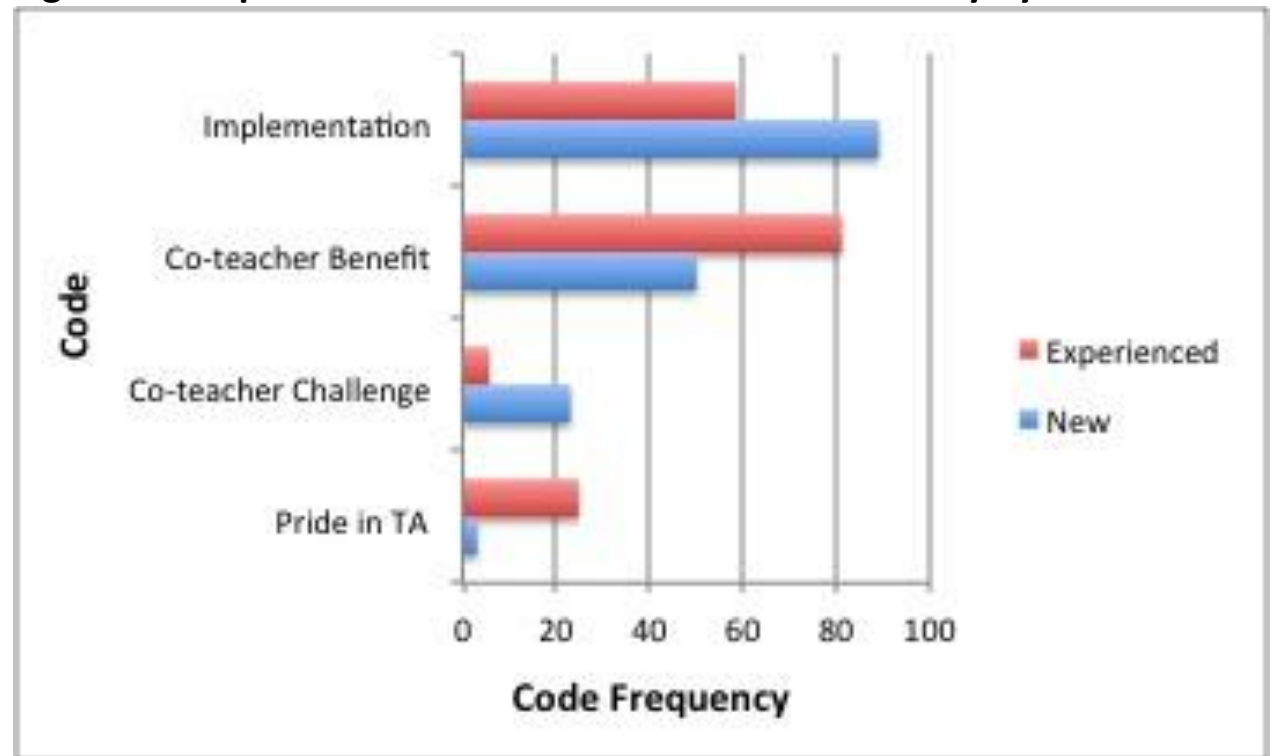

${ }^{1}$ Implementation code $\mathrm{N}=772$, Co-teacher Benefit code $\mathrm{N}=899$, Co-teacher Challenge code $\mathrm{N}=227$, and Pride in TA code $\mathrm{N}=194$.

\section{DISCUSSION}

In addition to affirming the value of the program for its intended purpose, the interview data showed an important and universal advantage. All participants viewed their TAs as colleagues/co-teachers and perceived this to be a benefit. Regardless of previous experience with S-L, academic discipline, length of teaching experience, TA recruitment method, or whether they chose to incorporate or were assigned to S-L, faculty universally found value in partnering with their undergraduate S-LTAs to improve teaching and learning in their classrooms.

It is noteworthy that all faculty participants reported appreciating both the logistical support and the collegial partnership with the TA. Our findings are consistent with a number of studies on partnering with undergraduates in courses without service-learning (Cook-Sather et al., 2014; Fingerson \& Culley, 2001; Owen, 2011). Our work extends these earlier findings to multiple academic disciplines and to service-learning, which has been identified in US national student surveys as a high-impact practice (Kuh, 2008).

It also provides some insight on how student-faculty partnerships may develop differently depending on specific faculty experiences. Importantly, although some faculty mentioned challenges with finding the right balance of independence or responsibility, we did not observe negative comments related to the time investment necessary for training and supervising undergraduate TAs. This is likely due to the highly structured TA training and semester-long mentoring and support provided by the S-L Program. The program shifts much of the instructional and management load from the faculty as it pertains to the TA, allowing more time and space for development of the collegial relationship with them that our faculty valued. This suggests a hidden benefit to a structured undergraduate teaching assistant program that may be broadly applicable in diverse disciplines both within and outside of the service-learning context. 
Previous studies have indicated a need for support for instructors, even senior faculty, who are implementing new pedagogies (Dancy, Henderson, \& Turpen, 2016; DiPietro \& Norman, 2014). Consistent with this, we saw differences between faculty who had taught three or fewer semesters of S-L courses and those who had taught more S-L courses, regardless of length of overall teaching experience (see Figure 2). For example, although all faculty mentioned benefits of the TA partnership in terms of improved course implementation and gaining a teaching colleague, faculty new to S-L spoke much more frequently about the logistical benefits, while faculty experienced with S-L more often mentioned a beneficial teaching partnership. This likely reflects an increase in confidence in using $S-L$ in the classroom with the shift from novice to experienced S-L practitioner. Newer S-L faculty also commented more on navigating challenges associated with the co-teacher relationships and finding the right balance.

These findings can help to inform faculty development efforts such as workshops, peer mentoring, or other resources provided to faculty new to $S$-L, or new to working with an undergraduate partner. New faculty might benefit from guidance from their more experienced peers on how to navigate the murky waters between a traditional supervisory relationship and a richer collaborative relationship. Hearing about the benefits from other faculty might help to shorten the time needed to fully develop a collaborative partnership with the TA.

Service-learning, perhaps even more so than many other pedagogical approaches, requires that faculty relinquish control; by introducing work with and for the community into teaching, faculty may experience a whole host of unpredictable challenges that they may not have previously encountered. The S-LTA not only helps the faculty member, students, and community partners navigate these challenges, but also becomes a colleague to the faculty member in the process. The insights offered through this collaborative relationship personally and professionally impacted faculty members who believed that course structure and the teaching endeavor itself were improved in spite of the complications that integrating this highimpact practice may involve. However, faculty more versed in the complexities of S-L seemed better positioned to shift to a more collegial partnership with their teaching assistants.

Interestingly, although the program was designed to engage teaching assistants directly in the day-to-day teaching and learning process, we found that faculty experience encompassed both this and an unforeseen enhancement of teaching practice, bringing together the two major (and overlapping) categories of student partnership identified by Healey et al. (2014): engagement in learning, teaching, and/or research itself and engagement in developing learning and teaching practice and policy. Applying the model of student co-creation of teaching and learning put forth by Bovill, Cook-Sather, Felten, Millard, and Moore-Cherry (2016) to our findings suggests that the TAs served consistently as consultants and, in some cases, as pedagogical co-designers. In describing a formal student consultant program, CookSather (2014) noted that both students and faculty experienced "multiplied perspectives," reporting new insights, increased self-awareness, greater understanding of others' perspectives, and adoption of a more shared approach to teaching and learning. This is consistent with our observations, despite the fact that the S-LTA program was designed specifically to address logistical issues in implementing service-learning, rather than provide consulting on teaching and learning. And while the teaching assistants in our program were not 
serving in the role of student representatives, the faculty perceived very similar unexpected benefits to interacting with their assistants as those reported by Curran (2017), who interviewed faculty and students involved in a students-as-representatives program.

Undergraduate teaching assistants are clearly meant to contribute to the instructional work of higher education institutions and ease the burdens on teachers. As such, they may be viewed in a transactional way, as resources that faculty may use or depend upon for completion of particular tasks. However, our findings indicate that they are contributing much more, and that this is not happening by accident, but rather through an intentional support and training infrastructure. The faculty that we interviewed reported developing collaborative partnerships with their teaching assistants, valuing their input and insights broadly. The extent to which the nature of the relationship shifted away from a reliance on the TA primarily for logistical support and towards a more collegial relationship in which the student was viewed as a true partner in teaching and learning varied based on the level of instructor experience in teaching service-learning courses. Experience with this pedagogy may be a proxy indicator of faculty confidence and thus willingness to relinquish control. In future studies it will be important to explore whether faculty confidence plays a major role in the development of collaborative partnerships with students and to what extent students realize that they are making truly valuable contributions to teaching and learning within and beyond the bounds of their roles as teaching assistants.

This research was reviewed and approved by the Institutional Review Board at Northeastern University.

\section{ACKNOWLEDGEMENTS}

The authors would like to thank the ADVANCE Office of Faculty Development at Northeastern University as well as all of the service-learning teaching assistants, their faculty partners, and community partners - past and present-for making this project possible.

\section{NOTE ON CONTRIBUTORS}

Gail Begley is Teaching Professor and Director of Undergraduate Studies in Biology and Co-Chair of the University Service-Learning Advisory Board at Northeastern University, Boston, USA where she teaches and develops curriculum in biology, including service-learning classes.

Rebecca Berkey is Director of Service-Learning and Co-Director of the Center of Community Service at Northeastern University, Boston, USA where she leads the integration of community engagement into teaching and learning across the disciplines.

Lisa Roe is Assistant Director of Service-Learning with the Center of Community Service at Northeastern University, Boston, USA where she directs the service-learning teaching assistant and student leader training programs. 
Hilary Schuldt is Director of Project and Team Strategy at the Center for Advancing Teaching and Learning Through Research at Northeastern University, Boston, USA where she contributes across the center's faculty and student initiatives.

\section{REFERENCES}

Abes, E. S., Jackson, G., \& Jones, S. R. (2002). Factors that motivate and deter faculty use of service-learning. Michigan Journal of Community Service Learning, 9(1), 1-17. Retrieved from https://quod.lib.umich.edu/m/mjcsl/3239521.0009.101?rgn=main;view=fulltext

Bass, R. (2012). Disrupting ourselves: The problem of learning in higher education. Educause Review, 47(2), 1-14. Retrieved from https://er.educause.edu/articles/2012/3/disruptingourselves-the-problem-of-learning-in-higher-education

Baxley, E. G., Probst, J. C., Schell, B. J., Bogdewic, S. P., \& Cleghorn, G. D. (1999). Programcentered education: A new model for faculty development. Teaching and Learning in Medicine, 11(2), 94-99. https://doi.org/10.1207/S15328015TL110207

Bovill, C., Cook-Sather, A., \& Felten, P. (2011). Students as co-creators of teaching approaches, course design, and curricula: Implications for academic developers. International Journal for Academic Development, 16(2), 133-145. http://dx.doi.org/10.1080/1360144X.2011.568690

Bovill, C., Cook-Sather, A., Felten, P., Millard, L., \& Moore-Cherry, N. (2016). Addressing potential challenges in co-creating learning and teaching: Overcoming resistance, navigating institutional norms and ensuring inclusivity in student-staff partnerships. Higher Education, 71(2), 195-208. http://dx.doi.org/10.1007/s10734-015-9896-4

Bringle, R., Hatcher, J., \& Games, R. (1997). Engaging and supporting faculty in service learning. Journal of Higher Education Outreach and Engagement, 2(1), 43-51. Retrieved from http://openjournals.libs.uga.edu/index.php/iheoe/article/view/287

Cook-Sather, A. (2014). Multiplying perspectives and improving practice: What can happen when undergraduate students collaborate with college faculty to explore teaching and learning. Instructional Science: An International Journal of the Learning Sciences, 42(1), 31-46. http://dx.doi.org/10.1007/s11251-013-9292-3

Cook-Sather, A., \& Motz-Storey, D. (2016). Viewing teaching and learning from a new angle: Student consultants' perspectives on classroom practice. College Teaching, 64(4), 168177. https://doi.org/10.1080/87567555.2015.1126802

Cook-Sather, A., Bovill, C., \& Felten, F. (2014). Engaging students as partners in learning and teaching: A guide for faculty. San Francisco, CA: Jossey-Bass.

Creswell, J. W. (2003). Research design: Qualitative, quantitative, and mixed method approaches. Thousand Oaks, CA: Sage Publications.

Curran, R. (2017). Students as Partners-good for students, good for staff: A study on the impact of partnership working and how this translates to improved student-staff engagement. International Journal for Students as Partners, 1(2), 1-16. https://doi.org/10.15173/ijsap.v1i2.3089

Dancy, M., Henderson, C., \& Turpen. C. (2016). How faculty learn about and implement research-based instructional strategies: The case of peer instruction. Physical Review 
Physics Education Research, 12(1), 1-17.

https://doi.org/10.1103/PhysRevPhysEducRes.12.010110

DiPietro, M., \& Norman, M. (2014). Using learning principles as a theoretical framework for instructional consultations. International Journal for Academic Development, 19(4), 281 292. https://doi.org/10.1080/1360144X.2013.837826

Dotolo, L. G. (1999). Faculty development: working together to improve teaching and learning. New Directions for Higher Education, 1999(106), 51-57. https://doi.org/10.1002/he.10606

Eby, K. K., \& Gilbert, P. R. (2000). Implementing new pedagogical models: Using undergraduate teaching assistants in a violence and gender learning community. Innovative Higher Education, 25(2), 127-142. https://doi.org/10.1023/A:1007576923195

Fingerson, L., \& Culley, A. (2001). Collaborators in teaching and learning: Undergraduate teaching assistants in the classroom. Teaching Sociology, 29(3), 299-315. https://doi.org/10.2307/1319189

Healey, M., Flint, A., \& Harrington, K. (2014). Engagement through partnership: Students as partners in learning and teaching in higher education. York, UK: Higher Education Academy. Retrieved from https://www.heacademy.ac.uk/engagement-throughpartnership-students-partners-learning-and-teaching-higher-education

Koslowski, F. (2006, April). Overcoming faculty resistance to assessment. Paper presented at the Undergraduate Assessment Symposium, North Carolina State University. Retrieved from http://www.ncsu.edu/assessment/symposium/presentations/A.10 Koslowski.pdf

Kuh, G. D. (2008). High-impact educational practices: What they are, who has access to them, and why they matter. Washington, DC: Association of American Colleges \& Universities.

Kuh, G., Donnell, K., \& Schneider, C. G. (2017). HIPs at ten. Change: The Magazine of Higher Learning, 49(5), 8-16. https://doi.org/10.1080/00091383.2017.1366805

Lazerson, M., Wagener, U., \& Shumanis, N. (2000). What makes a revolution? Change, The Magazine of Higher Learning 32(3), 12-20. https://doi.org/10.1080/00091380009601731

Matthews, K. E. (2016). Students as partners as the future of student engagement. Student Engagement in Higher Education Journal, 1(1), 1-5. https://journals.gre.ac.uk/index.php/raise/article/view/380/338

Mercer-Mapstone, L., Dvorakova, S. L., Matthews, K. E., Abbot, S., Cheng, B., Felten, P., Knorr, K., Marquis, E., Shammas, R., \& Swaim, K. (2017). A systematic literature review of students as partners. International Journal for Students as Partners, 1(1), 1-23. https://doi.org/10.15173/ijsap.v1i1.3119

Moustakas, C. E. (1994). Phenomenological research methods. Thousand Oaks, CA: Sage Publications.

Owen, J. E. (2011). Peer educators in classroom settings: Effective academic partners. New Directions for Student Services, 2011(133), 55-64. https://doi.org/10.1002/ss.384

Young, C. A., Shinnar, R. S., Ackerman, R. L., Carruthers, C. P., \& Young, D. A. (2007). Implementing and sustaining service-learning at the institutional level. Journal of Experiential Education, 29(3), 344-365. https://doi.org/10.1177/105382590702900306 